\title{
Thirty-four years of climatic selection in the land snail Theba pisana
}

\author{
MS Johnson \\ School of Animal Biology (M092), University of Western Australia, Crawley, Western Australia, Australia
}

\begin{abstract}
Few continuous, long-term studies have measured the intensity and variability of natural selection within a framework of clear adaptive hypotheses. In the snail Theba pisana, the proportion of effectively unbanded shells is higher in exposed habitats than in adjacent acacia thickets, which has been explained by microclimatic selection. Comparisons across an ecotone for 34 consecutive years determined the combined effects on morph frequencies of habitat and changes in weather conditions during summer. The long-term average ( \pm s.e.) frequency of effectively unbanded shells was $0.577 \pm 0.011$ in the open habitat when compared with $0.353 \pm 0.005$ in the acacia. The persistent association of shell banding with habitat accounted for $34 \%$ of the variation in morph frequencies. Differences among years were also large, representing $23 \%$ of the
\end{abstract}

variation. Higher proportions of effectively unbanded snails were associated with hotter, sunnier summers. Thus, temporal variation supports the hypothesis of microclimatic selection, consistent with the spatial association with habitat. Based on observed rates of change, the mean annual selection on this polymorphism was about 0.13 , but with a large variance: $s$ was as high as 0.5 , but $\leqslant 0.05$ in about $40 \%$ of the years. The large variance and frequent reversals in direction of selection indicate a potential for rapid genetic change, but with little net change in morph frequencies over three decades, highlighting the value of long-term continuous studies of populations facing natural environmental variation.

Heredity (2011) 106, 741-748; doi:10.1038/hdy.2010.114; published online 8 September 2010

Keywords: adaptation; ecotone; selection coefficient; shell banding; temperature; temporal variation

\section{Introduction}

The pervasiveness of natural selection is clear (see, for example, Pagel, 2009), but our understanding of the process continues to grow. Since the review of Endler (1986) showed that detectable selection in nature is common, several studies have documented rapid adaptation to experimental manipulation or environmental perturbation in nature (reviewed by Thompson, 1998; Carroll et al., 2007). Endler (1986) also showed, however, that selection is typically stronger in studies in perturbed or extreme environments, where equilibrium is less likely, and hence the capacity for rapid change may be realized only occasionally. Field studies of variation in quantitative traits have shown that selection can vary substantially over time, but more long time series are needed to determine the variability of intensity and direction of selection (reviewed by Hendry and Kinnison, 1999; Hoekstra et al., 2001; Hereford et al., 2004; Siepielski et al., 2009). For example, among the 89 time series recently reviewed by Siepielski et al. (2009), the median length was just 3 years, and only 11 studies spanned at least 20 years, 5 of which exceeded 30 years. Those authors also highlighted two other limitations in the temporal studies of natural selection: (1) studies are heavily biased towards vertebrates (for example, their

Correspondence: Professor MS Johnson, School of Animal Biology (M092), University of Western Australia, 35 Stirling Highway, Crawley, Western Australia 6009, Australia.

E-mail:msj@cyllene.uwa.edu.au

Received 7 May 2010; revised 30 June 2010; accepted 20 July 2010; published online 8 September 2010
11 longest studies were all of vertebrates, representing only 8 genera); and (2) it is easier to detect selection than to understand causes, and relatively few temporal studies (see, for example, Grant and Grant, 2002; McAdam and Boutin, 2003; Carlson and Quinn, 2007) test clear adaptive hypotheses. An exception to both limitations is the analysis of industrial melanism in the moth Biston betularia (for example, Cook and Turner, 2008), but additional, focused studies of invertebrates are clearly needed.

Studies of shell polymorphism in land snails show both the potential and the limitations of long-term studies. Likely mechanisms of selection are often clear in terms of selective predation or climatic selection (Jones et al., 1977; Clarke et al., 1978; Cain, 1983), allowing predictions of responses to changes in habitat or climate. Following the lead by Clarke and Murray (1962), several long-term studies have estimated rates of change and intensity of selection in snails, especially Cepaea nemoralis (see, for example, Murray and Clarke, 1978; Wall et al., 1980; Cain et al., 1990; Cameron, 1992, 2001; Cowie, 1992; Cook and Pettitt, 1998; Cowie and Jones, 1998; Cameron and Pokryszko, 2008; Ozgo and Kinnison, 2008). With few exceptions, these studies have compared morph frequencies at end points of intervals up to 50 years, rather than between successive years or generations. Results have been mixed, often with no change, and generally with modest selection coefficients. However, given the variability of intensity and direction of selection observed in other taxa, interpretation is difficult. In addition, temporal comparisons are most valuable if they are based on specific hypotheses, and interpretations of many longitudinal studies have been 
difficult because of the lack of clear expectations (Cook and Pettitt, 1998; Cowie and Jones, 1998). In this paper I examine shell polymorphism in the land snail Theba pisana, across an ecological gradient, over a period of 34 consecutive years as a test of predicted responses to both habitat and climatic variation.

T. pisana is genetically polymorphic for shell banding (Cain, 1984; Cowie, 1984). In common with polymorphisms in several land snails, banding in T. pisana is strongly associated with habitat, as pale, unbanded morphs are more common in open, exposed habitats, with higher frequencies of darker, banded snails in shrubby, shady habitats (Johnson, 1980; Heller, 1981). Although selective predation may contribute to this association, evidence at the Bold Park population, near Perth, Western Australia, suggests an important role for microclimatic selection. Mortality during the hot, dry summer is higher in the exposed, open habitat than in the adjacent Acacia thicket, and snails near the ecotone tend to take shelter in the Acacia bushes for summer aestivation (Johnson, 1981). The darker, fully banded snails heat up more rapidly than unbanded snails when exposed to sunlight, and they have a stronger preference for the sheltered aestivation sites (Johnson, 1981; Hazel and Johnson, 1990). This combination of contrasting microclimates and the behaviour of the snails favours the hypothesis of climatic selection. This population has been censused annually since 1977, allowing a temporal test of this hypothesis. Morph frequencies over the 34-year period were examined to determine: (1) whether the association of banding with habitat has persisted, (2) how much morph frequencies have changed, (3) the intensity and pattern of selection from one year to the next and (4) whether the changes are associated with summer temperature.

\section{Materials and methods}

\section{Study area and sampling}

The study site is an area of coastal dunes in the southwest corner of Bold Park $\left(31^{\circ} 57^{\prime} 06^{\prime} \mathrm{S}, 115^{\circ} 45^{\prime}\right.$ $21^{\prime}$ E) in City Beach, Perth. T. pisana is a circumMediterranean species, which was introduced in coastal areas of Perth in the 1890s, and the species was well established throughout the study area by the time this study began. Snails were collected each year from 1977 to 2010, along a $230 \mathrm{~m}$ transect across the transition between a dense thicket of Acacia scrub and an area of low, sparse dune vegetation (areas Acacia I and Open I of Johnson, 1980). The transect comprised contiguous $5 \times 5 \mathrm{~m}$ quadrats, except in the western portion of the Open habitat, where the dune vegetation was patchy and shifted between years. The length of the transect sampled varied among years, but always included the entire Open habitat and $\geqslant 35 \mathrm{~m}$ into the Acacia. Within each quadrat, three or four people systematically searched the ground and vegetation, attempting to collect all snails $\geqslant 10 \mathrm{~mm}$ in diameter (=adults and near-adults). The snails were scored for shell banding, and returned to their quadrats of origin, within 2 weeks of collection.

At each census except those in 1978-1983, the maximum height of vegetation was measured in each $1 \mathrm{~m}$ interval along the transect, and the average was recorded for each quadrat. Quadrats with $\geqslant 60 \%$ coverage by bushes were classified as Acacia and those with $\leqslant 40 \%$ as Open. In 12 of the years, the quadrat at the ecotone had intermediate cover, and was excluded from analyses. Samples were collected in autumn or winter (late March to early August), depending on the year. Movements of the snails cause seasonal variation in morph frequencies in the open habitat, within 15-20 m of the Acacia, but such seasonal variation within the Acacia habitat is low (Johnson, 1981).

\section{Banding polymorphism}

The shell of T. pisana is white, with varying numbers and intensities of brown bands, determined primarily by alleles at the banding locus, but with modifiers at other loci (Cain, 1984; Cowie, 1984). I classified shells simply as either effectively unbanded (EUB, in which bands are absent from the upper half of each whorl) or fully banded (FB, with some banding on the dorsal portion of the shell). EUB includes the dominant homozygote and heterozygotes at the banding locus, as well as banded snails in which upper bands are suppressed by modifier alleles at other loci. The last $90^{\circ}$ of the outermost whorl were ignored, because pigment is sometimes present in the newly formed shell, even of genetically unbanded snails (Cain, 1984). Both the colour (dark brown or yellowish; Cain, 1984; Cowie, 1984) and the intensity of banding were ignored to allow simple, consistent scoring of the shells. The collection and scoring of the snails were done as part of an undergraduate class project. To ensure consistency of scoring, each sample was scored independently by two groups of 3-5 students, and I examined any discrepancies. The results for each quadrat sample are presented in Supplementary Table 1.

\section{Analysis}

The proportion of EUB shells was calculated for each quadrat in each year, and analyses were based on the means among quadrats (Supplementary Table 2). Quadrats with $<10$ snails were excluded from all analyses (1.4\% of Acacia and $12.2 \%$ of Open samples). Average sizes of the remaining samples were $167 \pm 147$ (s.d.) in the Acacia and $97 \pm 95$ (s.d.) in the Open. Fixed-factor analysis of variance was used to quantify the effects of habitat (Acacia vs Open) and year of sampling (34 annual censuses) on the morph frequencies. Treating year as a fixed factor was appropriate because all years over the study period were included. Effect sizes were calculated as magnitudes of effects as described by Winer (1971, p. 428) for a factorial design.

Detailed analysis of temporal variation was restricted to the Acacia habitat. For each year, the proportions of EUB in each of the Acacia quadrats were averaged to provide the mean for that year. Restriction to the Acacia habitat allowed analysis of temporal variation, without confounding effects of habitat. Similar analysis in the Open habitat was less feasible, because errors of estimation of the mean frequencies of EUB were much higher in the Open than in the Acacia habitat: mean s.e. $=0.053$ (maximum $=0.133$ ) in the Open when compared with 0.023 (maximum $=0.042$ ) in the Acacia. This was because the numbers of snails were typically much lower in the Open, which also meant that in some years there were few quadrats with $N \geqslant 10$. Thus, there were 7 years in which $<3$ quadrats with $N \geqslant 10$ were there in the 
Open, and an additional 3 years with 3 quadrats when compared with 7 to 21 quadrats each year in the Acacia.

Depending on location, the life cycle of $T$. pisana varies between 1 and 2 years, with a post-reproductive die-off (Cowie, 1992; Baker, 2008). In the Bold Park population, reproduction occurs in autumn and early winter, depending on the rain. The snails aestivate above ground over the dry summer months. Some snails reproduce following their first summer, whereas others do not reproduce until after their second summer. Thus, the generation time is between 1 and 2 years, most likely varying with annual conditions. The intensity of natural selection was estimated annually (that is, within a generation), based on changes in the frequency of banding morphs from one year to the next.

Estimating selection is complicated by the multilocus determination of banding patterns, and by the simple, functional classification that was used in this study. Because the yearly sampling is largely within a generation, one approach is to estimate the selection required to cause the yearly changes in the frequencies of $\mathrm{FB}$ and EUB shells. In this case, $s=\left(1-\left(P_{0} / P_{1}\right)\right) /\left(1-P_{0}\right)$, where $P_{0}$ is the initial frequency of the favoured morph, and $P_{1}$ is the frequency in the following year. This short-term phenotypic approach assumes that the complications of Mendelian segregation are minimal.

A second estimate of selection was based on the genetics of the banding polymorphism (Cain, 1984; Cowie, 1984). As a first approximation, the FB condition is the recessive homozygote at the banding locus. Based on this single-locus model, selection against either FB or EUB was estimated using the equations of Clarke and Murray (1962), which assume that the genotypes begin each generation in Hardy-Weinberg equilibrium. Selection (s) was estimated on an annual basis, which is less than the generation time of between 1 and 2 years. The major caveat with this single-locus approach is that the modified phenotype '003', in which an allele at an unlinked locus converts genetically banded shells to effectively unbanded (Cain, 1984), is included in the dominant EUB phenotype at the banding locus. Because the 003 shells mask the genotype at the banding locus, the bias is towards underestimation of the true intensity of selection. The frequency of 003 shells was not measured in the annual censuses, and hence a more complex genetic model could not be used. In addition to estimating the intensity of selection for each annual interval, the formulas of Clarke and Murray (1962) were used to estimate average annual selection for trends over several years. Because data were available for each year, I used the estimates of the initial and final frequencies from regression of morph frequency on time, thereby reducing the error associated with using simply the observed end points.

As explained by Hereford et al. (2004), estimates of the absolute value of selection are biased upwards, because absolute errors of estimation are necessarily positive. To remove the bias of the annual estimates, the standard error of the difference between mean frequencies of EUB was taken as the expected difference due to sampling error. For observed difference sexpected difference, $\triangle E U B$ (and therefore $s$ ) was set to zero. If observed difference $>$ expected difference, the frequency of EUB in the second year was adjusted by either adding (if EUB had decreased) or subtracting (if EUB had increased) the expected difference in EUB between the successive years. This adjustment reduced the estimated absolute intensity of selection by removing the effects of sampling error, and it was applied only to comparisons of absolute values of $s$.

To test for an association of morph frequencies with climatic conditions, weather observations were obtained for Perth from 1975 through 2010 (Australian Bureau of Meteorology). The Perth recording station is $11 \mathrm{~km}$ east (inland) of the coastal study site. To test the hypothesis that hotter conditions favour EUB, six weather variables were recorded for each summer (December-February): average daily maximum temperature; number of days with maximum temperature $\geqslant 30^{\circ} \mathrm{C}$; number of days with maximum $\geqslant 40^{\circ} \mathrm{C}$; mean number of hours of sunshine per day; number of days with detectable rainfall; and amount of rain. It was expected that summer conditions would be more important for selection on the banding polymorphism. As a check of this expectation, the same variables (except days with temperatures $\geqslant 30$ or $\geqslant 40^{\circ} \mathrm{C}$ ) were also recorded for fall, winter and spring. Because the weather variables are highly correlated, principal components analyses were used to find composite measures of weather conditions in each season. Association of the frequency of EUB with each composite seasonal weather variable was thus tested by regression. The snails were up to 2 years old at the time of sampling, and hence the dependent variables were the averages of each weather variable over the 2 years preceding sampling.

\section{Results}

\section{Spatial and temporal variation}

Over the 34 years, there was a persistent association of morph frequencies with habitat, with a mean ( \pm s.e.) of $35.3 \pm 0.5 \%$ EUB in the Acacia when compared with $57.7 \pm 1.1 \%$ in the Open (Figure 1). Significant differences $(P<0.05, t$-tests) were found individually in 26 of the 33 years, including the 14 most recent ones, confirming the persistence of the association of morph frequencies with habitat. Over the course of the study, the average height of the canopy in the Acacia increased from 1.75 to $3 \mathrm{~m}$,

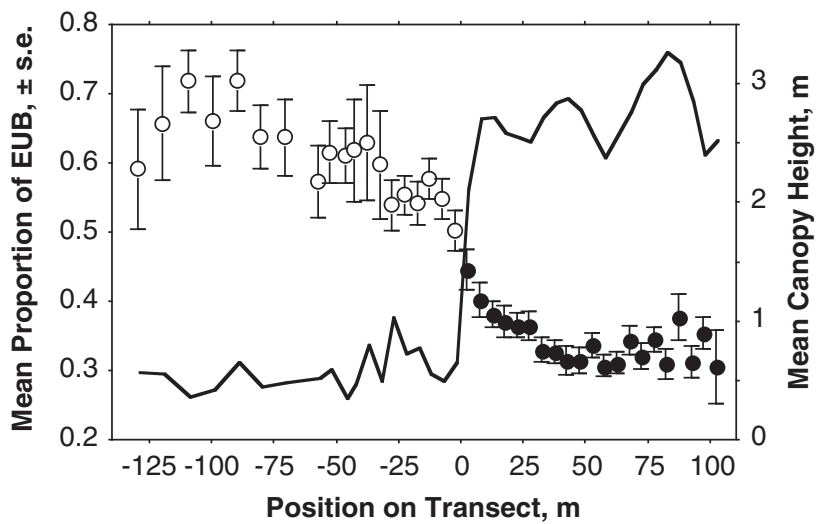

Figure 1 Mean ( \pm s.e.) proportion of effectively unbanded (EUB) shells and mean canopy height (solid line) along the transect relative to the position of the habitat boundary $(0 \mathrm{~m})$ over 34 years of sampling. Open circles denote open habitat and filled circles denote acacia habitat. 
Table 1 Analysis of the effects of habitat (open vs acacia) and year on proportion of effectively unbanded Theba pisana

\begin{tabular}{lrccrcc}
\hline Source & d.f. & SS & MS & \multicolumn{1}{c}{$F$} & P-value & \% Effect size \\
\hline Habitat & 1 & 7.708 & 4.708 & 560.205 & $<0.0001$ & 34.1 \\
Year & 33 & 3.467 & 0.108 & 12.502 & $<0.0001$ & 23.1 \\
Interaction & 32 & 0.809 & 0.025 & 2.917 & $<0.0001$ & 3.9 \\
Residual & 575 & 4.832 & 0.008 & & & \\
\hline
\end{tabular}

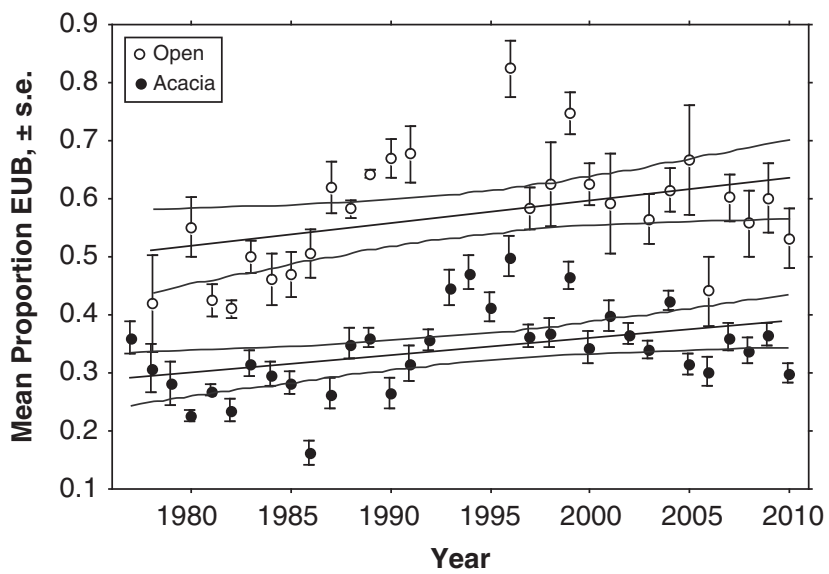

Figure 2 Mean ( \pm s.e) proportion of effectively unbanded (EUB) shells over time in the Open (open circles) and Acacia (filled circles) habitats. Only means based on $\geqslant 3$ quadrats with $N \geqslant 10$ snails are included. Regressions ( $\pm 95 \%$ confidence limits of means) are shown for each habitat.

and the Acacia spread $20 \mathrm{~m}$ into formerly Open habitat, but the boundary remained abrupt (Figure 1). The change in morph frequencies was also abrupt at the habitat boundary. The difference between habitats accounted for $34.1 \%$ of the total variation of morph frequencies among all samples (Table 1).

In addition to this difference between habitats, there was substantial variation among years, representing $23.1 \%$ of the total variance (Table 1). Although the interaction term was statistically significant, it was much smaller than the main effects, accounting for only $3.9 \%$ of the total (Table 1). As implied by the small interaction term, temporal changes were similar in the Open and Acacia habitats (Figure 2); the similarity was confirmed by the correlation between the proportions of EUB in the two habitats among years $(r=0.653$, d.f. $=25, P<0.001)$. This comparison of temporal change in the two habitats excluded quadrats in the Open that were within $15 \mathrm{~m}$ of the ecotone to minimize parallel changes because of movements of the snails between habitats. It also excluded the 7 years with means based on $<3$ quadrats in the Open habitat. In each habitat, there was a slight, but significant, trend of increasing proportions of EUB over time $\left(r^{2}=0.172, P=0.015\right.$ in the Acacia; $r^{2}=0.146$, $P=0.030$ in the Open).

However, variation around this trend was substantial, with large differences even from one year to the next. Within the Acacia habitat, morph frequencies differed significantly $(P<0.05, t$-test) between successive years in 17 of the 33 comparisons. The extent and pattern of change over longer periods depended on the intervals of
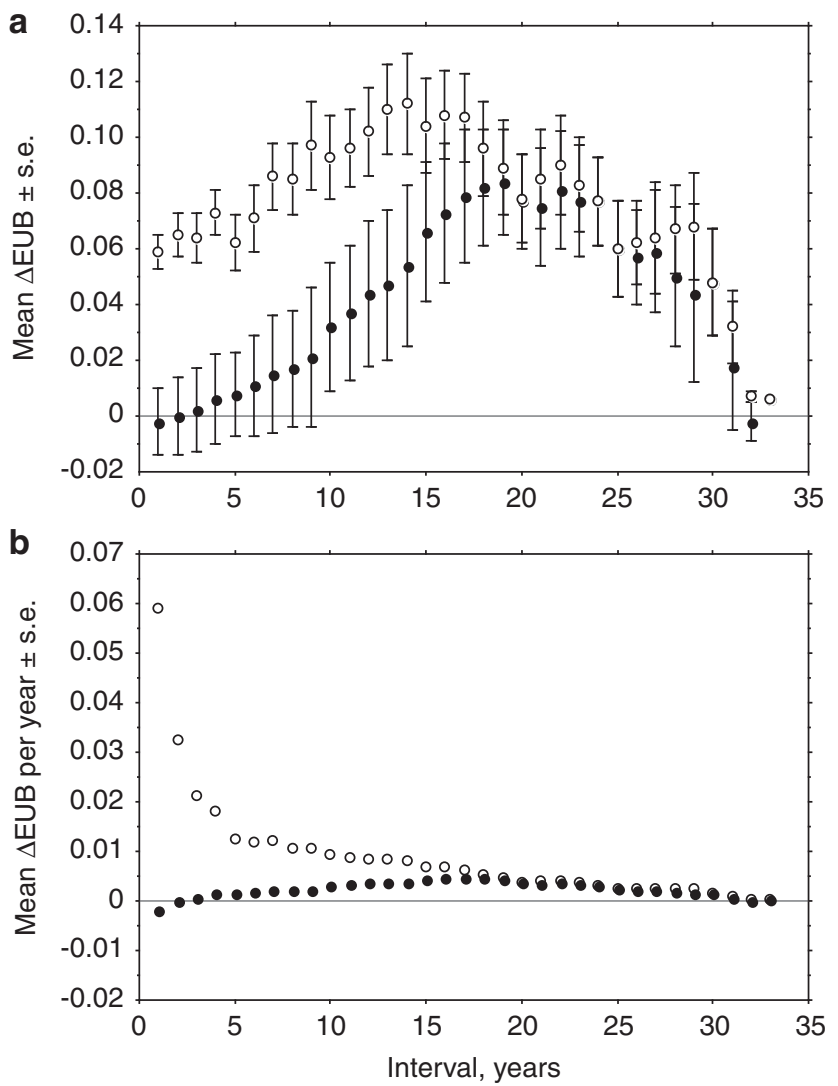

Figure 3 Mean changes in the frequency of effectively unbanded (EUB) snails within the Acacia habitat measured over different time intervals. (a) Accumulated directional (filled circles) and absolute (open circles) changes; and (b) directional (filled) and absolute (open) changes per year.

comparison. As the interval of comparisons increased, an average increase of EUB was evident, up to 17-19 years apart, but the comparisons at larger timescales (with less replication) showed a reversal (Figure 3a), confirming the cyclic component to the temporal changes evident in Figure 2. Thus, frequencies in 2010 were much the same as 33 years earlier, despite both the trend towards more EUB over the entire period and the large changes within the period. The plot of absolute change against time interval highlighted the importance of short-term reversals in the proportion of EUB: average absolute change in morph frequencies was 0.06 over 1 year, accumulating gradually to 0.11 in comparison to frequencies 14 years apart (Figure 3a). Calculation of the annual rate of change showed the importance of having the data for each year; because the direction of change varied, the rates of change were substantially highest for absolute change over a single year (Figure $3 \mathrm{~b}$ ). This is important for determining the intensity of selection in the next section.

\section{Natural selection}

Based on the single-locus model, the modest trend of increasing frequencies of EUB over the 34 years required selection against FB of only 0.015 per year in the Acacia habitat (Table 2), but this ignored the large variations around the trend. As a more informative analysis, 
average annual $s$ was estimated for each of the three periods in which morph frequencies changed in the same direction for at least three consecutive years, which gave values of $0.127-0.301$ (Table 2). These calculations showed that selection was strong over some periods, but they did not indicate the normal intensity of selection or its variation from one year to the next. Correcting for sampling bias, the mean ( \pm s.e.) absolute annual selection coefficient was $0.122 \pm 0.022$ for the phenotypic model, and $0.135 \pm 0.025$ for the single-locus model, a

Table 2 Estimates of mean ( \pm s.e.) intensity of selection per year based on temporal variation of morph frequencies in the Acacia habitat

\begin{tabular}{lcc}
\hline Method & Against & s \pm s.e. \\
\hline Based on trend interval & & \\
1977-2010 & FB & $0.015 \pm 0.004$ \\
$1977-1980$ & EUB & $0.211 \pm 0.054$ \\
$1982-1985$ & FB & $0.127 \pm 0.049$ \\
$1990-1993$ & FB & $0.301 \pm 0.040$ \\
& & \\
Direct year to year & Mixed & $0.122 \pm 0.022$ \\
$\quad$ Phenotypic & Mixed & $0.135 \pm 0.025$ \\
Single locus &
\end{tabular}

Abbreviations: EUB, effectively unbanded; FB, fully banded. nonsignificant difference. Variation around these means was considerable. Although individual estimates of annual $s$ were as high as 0.50 , the estimates were $<0.05$ in 14 of the 33 years (Figure 4 ).

To test the prediction that the frequency of EUB should be higher in years with hotter summers, morph frequencies were regressed on the composite weather variables. The principal component (PC) analysis of variables for each season produced clearly interpretable measures (Table 3). As predicted, frequencies of EUB in the Acacia habitat over the 34 years of this study were positively associated with hot, sunny summers in the 2 years preceding sampling, as represented by the average of summer PC1 (Figure 5; $r^{2}=0.204, P=0.007$ ). The same trend was found for summer PC1 separately in each of the two preceding summers, but was significant only for the immediately preceding summer $\left(r^{2}=0.190\right.$, $P=0.010)$. There was a weaker association with summer PC3, which represented the frequency of extremely hot days $\left(r^{2}=0.113, P=0.052\right)$. The association of EUB with hot summers was highlighted by the absence of significant association with any of the weather variables in fall, winter or spring $\left(r^{2} \leqslant 0.023\right.$ and $P>0.39$ in all cases). The intensity of selection was also associated with summer conditions, and the best predictor of $s$ was average maximum summer temperature of two summers preceding collection $\left(r^{2}=0.206, P=0.008\right.$ for a

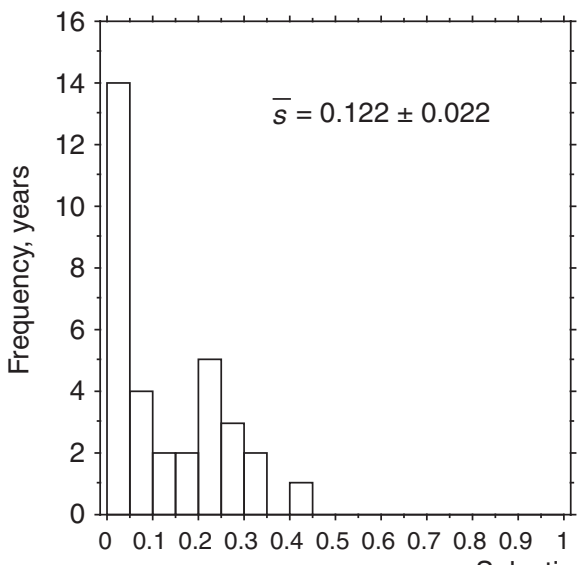

b

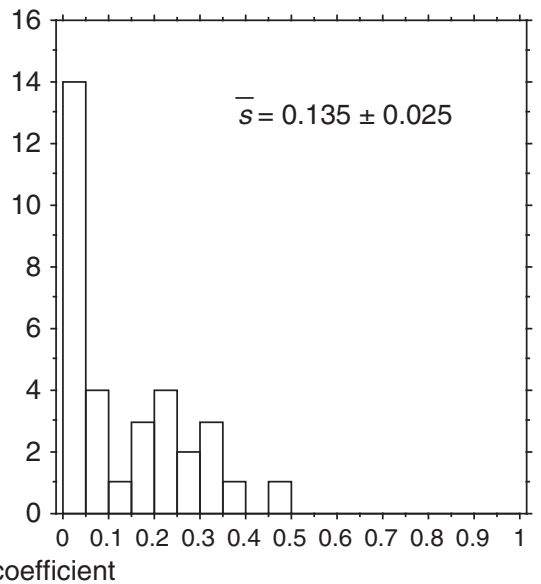

Figure 4 Frequency distribution of absolute annual selection coefficients estimated from (a) changes in phenotypic frequencies and (b) singlelocus model.

Table 3 Loadings (correlations) of weather variables on principal components (PCs) for each season based on data from March 1975 to February 2010

\begin{tabular}{|c|c|c|c|c|c|c|c|c|c|}
\hline & \multicolumn{3}{|c|}{ Summer } & \multicolumn{2}{|c|}{ Fall } & \multicolumn{2}{|c|}{ Winter } & \multicolumn{2}{|c|}{ Spring } \\
\hline & PC1 (50.8) & PC2 (19.3) & PC3 (14.2) & PC1 (56.4) & PC2 (25.5) & PC1 (63.3) & PC2 (20.7) & PC1 (50.3) & PC2 (25.4) \\
\hline Mean $T_{\max }$ & 0.714 & 0.549 & -0.166 & -0.290 & 0.930 & -0.506 & 0.862 & 0.819 & 0.087 \\
\hline Sunshine per day & 0.777 & -0.433 & -0.148 & -0.869 & 0.057 & -0.863 & -0.214 & 0.824 & 0.188 \\
\hline Rainfall & -0.752 & 0.385 & -0.155 & 0.771 & 0.387 & 0.848 & 0.141 & -0.134 & 0.979 \\
\hline Rain days & -0.866 & 0.303 & 0.136 & 0.908 & 0.024 & 0.901 & 0.147 & -0.803 & 0.118 \\
\hline Days $\geqslant 30^{\circ} \mathrm{C}$ & 0.624 & 0.608 & -0.260 & - & - & - & - & - & - \\
\hline Days $\geqslant 40^{\circ} \mathrm{C}$ & 0.478 & 0.244 & 0.833 & - & - & - & - & - & - \\
\hline
\end{tabular}

Loadings $\geqslant 0.5$ are in bold.

Percent variance represented is shown in parentheses for each component. 


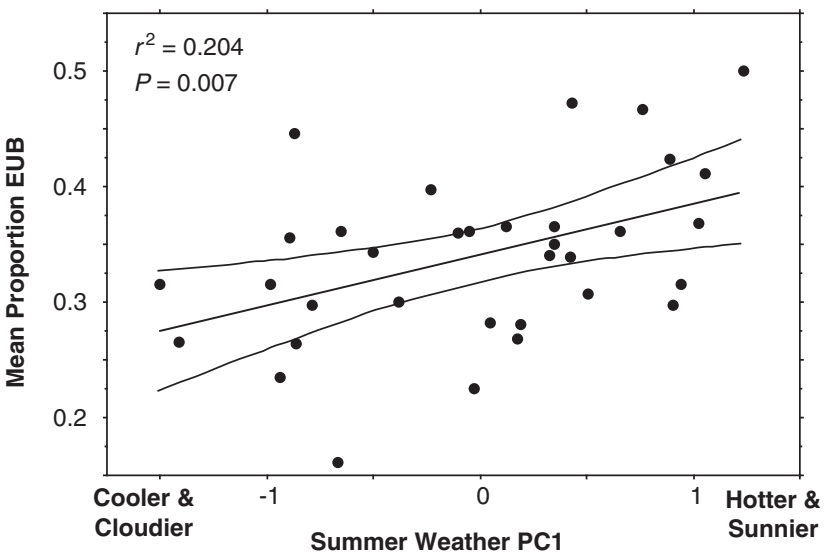

Figure 5 Linear regression ( $\pm 95 \%$ confidence limits of mean) of the frequency of effectively unbanded (EUB) snails in the Acacia habitat on the first principal component of summer weather variables, averaged over the two summers before sampling.

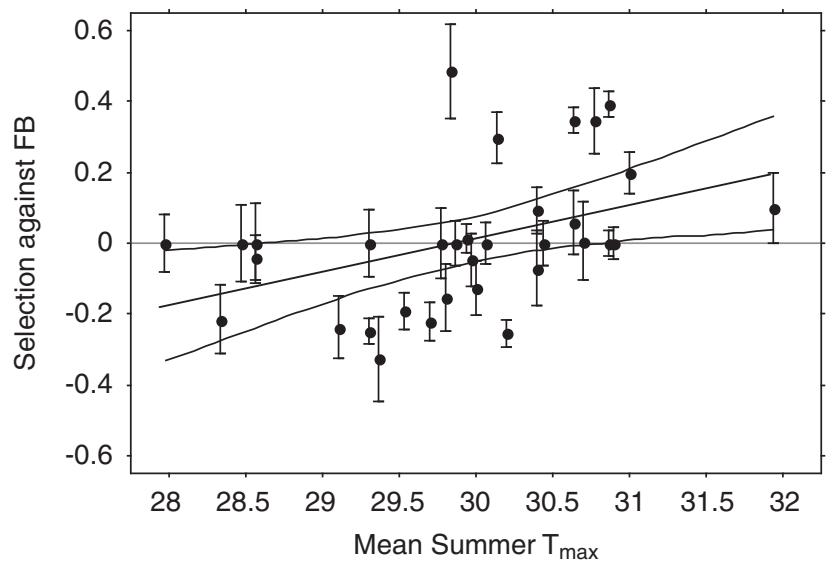

Figure 6 Linear regression ( $\pm 95 \%$ confidence limits of the mean) of $s$ ( \pm s.e., single-locus model) on mean maximum temperature of two summers preceding sampling. Positive $s$ is selection against FB, negative $s$ against EUB.

the phenotypic model; $r^{2}=0.180, P=0.014$ for the singlelocus model). Based on the regression of $s$ on summer $T_{\text {max }}$ in the acacia habitat EUB was favoured, on average, when average maximum temperature exceeded $30^{\circ} \mathrm{C}$, and $\mathrm{FB}$ was favoured $<30^{\circ} \mathrm{C}$, although there was substantial variation (Figure 6).

\section{Discussion}

\section{Spatial and temporal variation}

This study adds to the growing evidence that: (1) populations have the capacity for rapid genetic change, but (2) strong selection is special rather than persistent and (3) reversals of the direction of selection are common. The long time series also adds useful perspectives for understanding selection on the banding polymorphism in $T$. pisana. Despite substantial changes from year to year and a $20 \mathrm{~m}$ shift of the habitat boundary, morph frequencies differed between habitats persistently over the 34 years. The combination of spatial and temporal patterns indicates a polymorphism that responds to changing conditions. The abruptness of the genetic change at the habitat boundary is maintained partly by habitat choice (Johnson, 1981; Hazel and Johnson, 1990), but the differences at $\geqslant 100 \mathrm{~m}$ either side of the boundary are well beyond the distances the snails move. The association of morph frequencies with hot, sunny summers (and not with conditions in other seasons) supports previous evidence that climatic selection is important in this species, and that microclimatic selection is probably a major reason for the differences in morph frequencies between the Open and Acacia habitats.

As a species primarily of Mediterranean climates, T. pisana aestivates during the hot, dry summer months. At the Bold Park site, abundance of snails over the 34 years of this study was negatively associated with hotter summers in the open habitat, but not in the acacia (M Johnson, unpublished data), indicating more stressful conditions in the exposed habitat. Temperatures of aestivating

T. pisana in sunshine have been recorded to be up to $7^{\circ} \mathrm{C}$ higher than those at the same height above the ground in the shade (McQuaid et al., 1979), and the snails select sites off the ground or in the shade to reduce exposure to the sun (McQuaid et al., 1979; Cowie, 1985). In addition, FB T. pisana heat up more quickly and reach higher temperatures than their EUB counterparts, and they select less exposed microhabitats for aestivation (Hazel and Johnson, 1990). Thus, the combination of evidence is that differences in summer temperature and exposure to the sun underlie the spatial as well as the temporal variations of morph frequencies.

The evidence from the temporal variation also implies, as expected, that selection is due at least mainly to effects on survival rather than on reproductive fitness. This is because the frequency of EUB is associated with hot, sunny conditions in the summer immediately preceding sampling, as well as in the two preceding summers combined. Many of the snails had experienced only the immediately preceding summer, and thus had not yet reproduced at the time of collection. The evidence for selective mortality by temperature is strong, but indirect, as it has not been tested experimentally. The intensity of selection and its association with weather conditions revealed here allow prediction of the conditions and sizes of experiments required to detect selective mortality directly.

Although climatic selection affects the banding polymorphism in T. pisana, two related questions stand out: how is the polymorphism maintained, and what are the advantages of fully banded shells? Pale shells have an obvious advantage in hot, sunny conditions, but the persistence of the polymorphism and the reversals of selection imply a counter advantage for FB snails; that is, there must be a balance between temperature and some other selective force. The interpretation of Heller (1981) was that EUB T. pisana are favoured by climatic selection, whereas FB snails are favoured by being better camouflaged in nearly all habitats. This is the most likely answer and is supported by local departures from the predicted association with habitat, where predators are abundant (Heller and Gadot, 1984), but it remains to be tested directly. The present temporal study provides further evidence for the shifting balance of opposing forces of selection, but it sheds no direct light on the possibility of selective predation. 
Regardless of the exact mechanisms, however, oscillation of the direction of selection can help to maintain variation (see, for example, Reimchen and Nosil, 2002; Bell, 2010), and the reversals associated with fluctuating temperatures in $T$. pisana retard long-term changes in morph frequencies. The slight trend towards higher frequencies of EUB shells is consistent with the long-term global trend towards higher temperatures, but the variation around that trend dominates. Based on records since 1944, Perth has had an average increase of summer maximum temperatures of $0.022{ }^{\circ} \mathrm{C}$ per year (Australian Bureau of Meteorology), but the average absolute annual change has been $0.85^{\circ} \mathrm{C}$, nearly 40 times the underlying trend. Furthermore, because temperatures were well above the trend line in the late 1970s, no significant increase in average maximum temperature is evident over the 34 years of this study, highlighting the importance of variations around the long-term trend. The results for $T$. pisana show adaptive tracking of these short-term fluctuations, indicating both the responsiveness of the banding polymorphism and the importance of the long-term annual sampling to recognize that responsiveness.

\section{Intensity of natural selection}

Although there are reviews of the intensity of natural selection on quantitative traits in natural populations (Hendry and Kinnison, 1999; Hoekstra et al., 2001; Hereford et al., 2004; Siepielski et al., 2009), they measure the intensity of selection in terms of s.d. of the phenotypic variation, which cannot be compared directly with the selection coefficients estimated here. Comparisons are possible with previous studies of shell polymorphism in land snails, mostly in the genus Cepaea, and the responsiveness in T. pisana at Bold Park is generally greater. In this study, the two methods of estimating annual selection coefficients gave indistinguishable values, although the estimates of selection for the single-locus model may even be underestimates because they ignore the effect of the 003 modifier, which converts genetically banded snails to EUB. In a sample of 105 EUB snails in the acacia in 2009, 20 were 003. Taken at face value, this implies that $s$ may have been underestimated by nearly $20 \%$ for the single-locus model because that proportion of individuals is shielded from selection at the banding locus. This proportion presumably varies among years and sites, but the downward bias of estimates of $s$ highlights the contrast with previous results in land snails. Even the average intensity of selection detected in T. pisana at Bold Park is greater than that found in nearly all long-term studies of shell polymorphisms in land snails. For example, representative comparisons in Cepaea in the United Kingdom at intervals of 4-50 years found single-locus $s$ of $0-0.07$, with an average of 0.02 (Clarke and Murray, 1962; Murray and Clarke, 1978; Arthur et al., 1993; Cook and Pettitt, 1998; Cowie and Jones, 1998). These are estimates of $s$ per generation (generally 3 to 4 years in Cepaea), compared with the average annual $s$ of about 0.13 found for T. pisana in this study.

This contrast could be because of differences between taxa, different circumstances or bias in the estimation of selection. Only continuous, long time series can determine which causes are important, and nearly all long-term comparisons have been between end points decades apart rather than continuous time series. This limitation was recognized from the earliest long-term estimates of selection in Cepaea (Clarke and Murray, 1962). The present study highlights the potential extent of the problem, as the apparent rate of change (and hence of selection) is much higher when estimated annually than over decades. However, an exceptional, continuous study of a population of $C$. nemoralis for 16 years detected little if any selection (Cain et al., 1990) in contrast to T. pisana in the Bold Park population, and hence the effects of taxon or circumstance are probably important.

Possible explanations of slow change in populations of Cepaea include a relatively long generation time (typically 3 to 4 years), greater long-distance gene flow than indicated from mark-recapture experiments and fluctuating climatic conditions (Cook and Pettitt, 1998). The shorter generation of $T$. pisana favours rapid change, but relatively extreme climatic conditions may also be important. Cowie (1992) studied morph frequencies in a population of $T$. pisana in Wales for 13 consecutive years, and found stable spatial patterns with no significant temporal variation. The more extreme summer conditions faced by the population at Bold Park may well explain this contrast, highlighting the difficulty of extrapolating across both taxa and local environments. Related to this difficulty is the importance of testing predicted patterns of temporal change in response to relevant environmental variables, a point emphasized by Cowie and Jones (1998) for land snails, and more generally by others (see Reimchen and Nosil, 2002 for an example, and Siepielski et al., 2009 for a review).

Indeed, an exception to slow change in populations of Cepaea is the adaptation of the Polish populations of C. nemoralis over 18-28 years following their establishment in contrasting habitats (Ozgo and Kinnison, 2008). Changes were in the expected direction, with estimated selection coefficients of $0.24-0.42$ per generation, much higher than those in other temporal studies of that species. Thus, where directional selection was clearly predicted, it was found. The temporal analysis of T. pisana provides a perspective on likely rates of adaptation to such changes in habitat. Based on the long-term averages at the Bold Park site, if the acacia habitat were transformed to open habitat, the frequency of EUB shells would be expected to increase from about 0.35 to 0.60 . For that change to occur within a single year, selection would have to be about 0.75 against the FB snails, outside the range of $s$ seen in this study. The same change over 5 years would require $s=0.22$, well within the range found here. Thus, adaptation to a sudden change in habitat would probably occur well within 5 years, again illustrating the responsiveness of the banding polymorphism in T. pisana.

An important feature of this study is that it is of a wellestablished population, under 'normal' conditions, rather than of a new population or one responding to a recently disturbed environment. Although selection may be modest in most years, the average $s$ of about 0.13 is substantial. It represents an average annual, recurrent genetic load of $7.4 \%$, with loads in individual years as high as $27 \%$. In a 20 -year study of abundance of T. pisana at a site in South Australia, more than tenfold decreases in population density were commonly seen over summer (Baker, 2008), indicating the potential for this species to 
absorb substantial load. The fact that strong selection generally does not persist means that even with occasionally very strong selection, populations can recover rapidly. This capacity for absorbing genetic load is an important consideration in the ability of $T$. pisana to respond genetically to changes in conditions, and may contribute to its success as an invasive species.

\section{Conflict of interest}

The author declares no conflict of interest.

\section{Acknowledgements}

The annual collections were done as a project by my undergraduate class in genetics and evolution, and I thank the 977 students who contributed, as well as the 16 graduate students who helped with supervision. Drs Robert Black, Wade Hazel, Jason Kennington and Geoffrey Lewis also helped in various ways.

\section{References}

Arthur W, Phillips D, Mitchell P (1993). Long-term stability of morph frequency and species distribution in a sand-dune colony of Cepaea. Proc R Soc London B 251: 159-163.

Baker GH (2008). The population dynamics of the mediterranean snails Cernuella virgata, Cochlicella acuta (Hygromiidae) and Theba pisana (Helicidae) in pasture-cereal rotations in South Australia: a 20-year study. Aust J Exp Agric 48: 1514-1522.

Bell G (2010). Fluctuation selection: the perpetual renewal of adaptation in variable environments. Phil Trans $R$ Soc London B 365: 87-97.

Cain AJ (1983). Ecology and ecogenetics of terrestrial molluscan populations. In: Russell-Hunter WD (ed). The Mollusca, Vol 6, Ecology. Academic Press: New York.

Cain AJ (1984). Genetics of some morphs in the land snail Theba pisana. Malacologia 25: 381-411.

Cain AJ, Cook LM, Currey JD (1990). Population size and morph frequency in a long-term study of Cepaea nemoralis. Proc R Soc London B 240: 231-250.

Cameron RAD (1992). Change and stability in Cepaea populations over 25 years-a case of climatic selection. Proc $R$ Soc London B 248: 181-187.

Cameron RAD (2001). Cepaea nemoralis in a hostile environment: continuity, colonizations and morph-frequencies over time. Biol J Linnean Soc 74: 255-264.

Cameron RAD, Pokryszko BM (2008). Variation in Cepaea populations over 42 years: climatic fluctuations destroy a topographical relationship of morph frequencies. Biol J Linnean Soc 95: 53-61.

Carlson SM, Quinn TP (2007). Ten years of varying lake level and selection on size-at-maturity in sockeye salmon. Ecology 88: 2620-2629.

Carroll SP, Hendry AP, Reznick DN, Fox CW (2007). Evolution on ecological time-scales. Funct Ecol 21: 387-393.

Clarke B, Arthur W, Horsley DT, Parkin DT (1978). Genetic variation and natural selection in pulmonate snails. In: Fretter V, Peake J (eds). The Pulmonates, Vol. 2A, Systematics, Evolution and Ecology. Academic Press: New York. pp 271-290.

Clarke B, Murray J (1962). Changes of gene-frequency in Cepaea nemoralis (L.); the estimation of selective values. Heredity 17: 467-476.

Cook LM, Pettitt CWA (1998). Morph frequencies in the snail Cepaea nemoralis: changes with time and their interpretation. Biol J Linnean Soc 64: 137-150.
Cook LM, Turner JRG (2008). Decline of melanism in two British moths: spatial, temporal and inter-specific variation. Heredity 101: 483-489.

Cowie RH (1984). Ecogenetics of Theba pisana (Pulmonata: Helicidae) at the northern edge of its range. Malacologia 25: 361-380.

Cowie RH (1985). Microhabitat choice and high temperature tolerance of the land snail Theba pisana (Mollusca: Gastropoda). J Zool Lond 207: 201-211.

Cowie RH (1992). Shell pattern polymorphism in a 13 year study of the land snail Theba pisana (Müller) (Pulmonata: Helicidae). Malacologia 34: 87-97.

Cowie RH, Jones JS (1998). Gene frequency changes in Cepaea snails on the Marlborough Downs over 25 years. Biol J Linnean Soc 65: 233-255.

Endler JA (1986). Natural Selection in the Wild. Princeton University Press: Princeton, NJ.

Grant PR, Grant BR (2002). Unpredictable evolution in a 30-year study of Darwin s finches. Science 296: 707-711.

Hazel WN, Johnson MS (1990). Microhabitat choice and polymorphism in the land snail Theba pisana (Müller). Heredity 65: 449-454.

Heller J (1981). Visual versus climatic selection of shell banding in the landsnail Theba pisana in Israel. J Zool Lond 194: 85-101.

Heller J, Gadot M (1984). Shell polymorphism of Theba pisanathe effects of rodent distribution. Malacologia 25: 349-354.

Hendry AP, Kinnison MT (1999). The pace of modern life: measuring rates of microevolution. Evolution 53: 1637-1653.

Hereford J, Hansen TF, Houle D (2004). Comparing strengths of directional selection: how strong is strong? Evolution 58: 2133-2143.

Hoekstra HE, Hoekstra JM, Berrigan D, Vigneri SN, Hoang A, Hill CE et al. (2001). Strength and tempo of directional selection in the wild. Proc Natl Acad Sci USA 98: 9157-9160.

Johnson MS (1980). Association of shell banding and habitat in a colony of the land snail Theba pisana. Heredity 45: 7-14.

Johnson MS (1981). Effects of migration and habitat choice on shell banding frequencies in Theba pisana at a habitat boundary. Heredity 47: 121-133.

Jones JS, Leith BH, Rawlings P (1977). Polymorphism in Cepaea: a problem with too many solutions? Ann Rev Ecol Syst 8: 109-143.

McAdam AG, Boutin S (2003). Variation in viability selection among cohorts of juvenile red squirrels (Tamiasciurus hudsonicus). Evolution 57: 1689-1697.

McQuaid CD, Branch GM, Frost PGH (1979). Aestivation behaviour and thermal relations of the pulmonate Theba pisana in a semi-arid environment. J Therm Biol 4: 47-55.

Murray J, Clarke B (1978). Change of gene frequency in Cepaea nemoralis over fifty years. Malacologia 17: 317-330.

Ozgo M, Kinnison MT (2008). Contingency and determinism during convergent contemporary evolution in the polymorphic land snail Cepaea nemoralis. Evol Ecol Res 10: 721-733.

Pagel M (2009). Natural selection 150 years on. Nature 457: 808-811.

Reimchen TE, Nosil P (2002). Temporal variation in divergent selection on spine number in threespine stickleback. Evolution 56: 2472-2483.

Siepielski AM, DiBattista JD, Carlson SM (2009). It's about time: the temporal dynamics of phenotypic selection in the wild. Ecol Lett 12: 1261-1276.

Thompson JN (1998). Rapid evolution as an ecological process. Trends Ecol Evol 13: 329-332.

Wall S, Carter MA, Clarke B (1980). Temporal changes of gene-frequencies in Cepaea hortensis. Biol J Linnean Soc 14: 303-317.

Winer BJ (1971). Statistical Principles in Experimental Design. McGraw-Hill Kogakusha Ltd: Sydney.

Supplementary Information accompanies the paper on Heredity website (http://www.nature.com/hdy) 